\title{
Peran Media Sosial Dalam Memperkuat Loyalitas Pada Merek
}

\author{
Sartikah, G.Razati, D.H.Utama \\ Universitas Pendidikan Indonesia \\ sartikah@student.upi.edu
}

\begin{abstract}
The purpose of this study is to describe of social media and brand loyalty. In addition, to determine the effect of social media on brand loyalty. this type of research is descriptive and verifikatif, by using online survey method. Sampling technique used is simple random sampling. The sample in this study amounted to 235 people with object of this research is Teh Botol Sosro. Data analysis techniques in this study using a simple linear regression analysis. the results of this study show the social media and brand loyalty categorized high on the continuum line. The result of correlation calculation of social media variables have a significant influence on brand loyalty
\end{abstract}

\begin{abstract}
ABSTRAK
Tujuan dari penelitian ini adalah untuk mengetahui gambaran mengenai media sosial dan loyalitas merek. Selain itu, untuk mengetahui adanya pengaruh media sosial terhadap loyalitas merek. Jenis penelitian ini adalah deskriptif dan verifikatif, dengan menggunakan metode online survey. Teknik sampling yang digunakan peneliti adalah simple random sampling dengan mengambil sampel dalam penelitian ini berjumlah 235 orang. Objek penelitian ini adalah Teh Botol Sosro. Teknik analisis data pada penelitian ini menggunakan analisis regresi linear sederhana. Hasil penelitian ini menunjukan bahwa media sosial dan loyalitas merek dikategori tinggi pada garis kontinum. Hasil perhitungan korelasi variabel media sosial memiliki pengaruh yang signifikan terhadap loyalitas merek.
\end{abstract}

ARTICLE INFO: Article history:

Received 9 Februari 2018

Revised 12 Februari 2018

Accepted 13 Februari 2018

Available online 24 Mei 2018

\section{Keywords:}

Brand Loyalty, Fanpage Facebook,Social Media,

Teh Botol Sosro

\section{Kata Kunci: \\ Fanpage Facebook, Loyalitas Merek, Media Sosial, Teh Botol Sosro}

\section{PENDAHULUAN}

Pemasaran merupakan kegiatan penting yang dilakukan perusahaan untuk bertujuan memenuhi kebutuhan dan keinginan masyarakat melalui suatu produk yang diharapkan dapat memberikan manfaat bagi konsumen. Selain itu pemasaran ditujukan untuk meningkatkan keuntungan bagi perusahaan. Menurut AMA (American Marketing Association) yang dikutip oleh Kotler dan Keller (2012:5) definisi pemasaran adalah "Marketing is the activity, set of institutions, and processes for creating, communicating, delivering, and exchanging offerings that have value for customer, clients, partners and society at large". Pemasaran adalah sebuah kegiatan, fungsi organisasi dan serangkaian proses untuk menciptakan, mengkomunikasikan dan memberikan nilai kepada pelanggan, klien, mitra kerja dan masyarakat luas pada umumnya.

$$
\text { Pesatnya pertumbuhan dalam }
$$
industri makanan dan minuman menyebabkan banyak merek bermunculan dan bersaing untuk merebut pangsa pasar di 
Indonesia. Saat ini dalam industri makanan dan minuman mengalami pertumbuhan sebesar $8,16 \%$ dibandingkan pada tahun lalu. Meningkatnya jumlah penduduk dan pertumbuhan masyarakat middle class income, maka peningkatan daya beli masyarakat, dan pesatnya gerai ritel modern menjadi pendorong permintaan industri makanan dan minuman. Kajian Bank Mandiri awal tahun 2015 menyebutkan data BPS selama 10 tahun terakhir menunjukan rata-rata pengeluaran per kapita per bulan untuk makanan dan minuman sebesar $51 \%$ dari total pengeluaran. Sementara itu, Euromonitor memperkirakan pertumbuhan rata-rata per tahun pasar makanan dalam kemasan dan minuman ringan selama 20132017 akan berada diatas angka 10\% (Sumber: Warta Ekonomi tahun 2015 hal.45-46). Hal ini akan menyebabkan persaingan semakin ketat, sehingga perusahaan akan semakin berupaya meningkatkan layanan dan perubahan dalam mempertahankan mereknya dipasaran. Salah satu yang harus dipertahankan oleh perusahaan adalah kesetiaan pelanggan dalam menggunakan produk.

Perkembangan industri saat ini menyebabkan perusahaan semakin berupaya bersaing di pasaran. Banyaknya bermunculan merek-merek makanan dan minuman membuat konsumen berpikir untuk mencoba merek yang lain. Ini terjadi pada produk minuman dalam kemasan yang siap diminum atau biasa disebut dengan minuman Ready To Drink (RTD) semakin marak dijual dipasaran. Adanya produkproduk minuman dalam kemasan yang siap untuk diminum atau biasa disebut dengan minuman Ready To Drink (RTD) semakin marak dijual dipasaran, mengingat kebiasaan masyarakat saat ini yang menyukai sesuatu yang instan dan praktis sekaligus adanya kebutuhan dari masyarakat untuk memenuhi kebutuhan mereka akan rasa haus.

Fenomena tersebut dapat dilihat dari adanya persentase mengenai pertumbuhan industry minuman ditahun 2015 yang diestemasi $11 \%$ - 12\%, melampaui pertumbuhan industri menilai ruang tumbuh untuk sektor minuman dinilai masih lebih besar dengan penetrasi yang masih sangat rendah dibandingkan dengan makanan, (consume! Consumer Buisness Media, diakses 15 Desember 2015).

Menyasar pasar red ocean dengan pemain yang banyak dan persaingan yang ketat bukan perkara mudah di kategori Ready to Drink (RTD) Tea. Puluhan merek terlihat bertarung sengit untuk menguasai pangsa pasar dan menjadi market leader. Teh Botol Sosro merupakan market leader dan pionir di pasar RTD, namun saat ini di berdasarkan data Top Brand Index (TBI) mulai terlihat menurun. Tiga tahun kebelakang mengalami penurunan yang cukup signifikan terlihat berdasarkan grafik dibawah ini, pada tahun 2016 berada pada angka 33,8\%. Menurun signifikan dari tahun 2015 sebesar 14,0. Sedangkan Top Brand Index (TBI) Teh Pucuk Harum melonjak tajam hingga enam kali lipat dari tahun sebelumnya. Jika pada tahun 2015 Teh Pucuk Harum menempati posisi ke-6 dengan TBI 4.1\%, tahun 2016 TBI Teh Pucuk Harum mencapai 24.8\%. Perolehan ini mendudukkan Teh Pucuk Harum di posisi ke-2 dengan gap indeks hanya terpaut $9.0 \%$ dari market leader Teh Botol Sosro.

Saat ini pengguna internet pada 2017,eMarketer memperkirakan netter Indonesia akan mencapai 112 juta orang, mengalahkan Jepang di peringkat ke-5 yang pertumbuhan jumlah pengguna internetnya lebih lamban. Penggunaan media sosial Facebook salah satu yang digunakan konsumen untuk mengetahui suatu produk dan ikut terlibat dalam kegiatan yang di adakan oleh produsennya. Percakapan antara perusahaan dengan konsumen di media sosial memiliki keefektifan biaya untuk meningkatkan kesadaran merek, serta meningkatkan loyalitas. Dengan demikian, dapat dikatakan bahwa media sosial membantu perusahaan untuk membangun loyalitas merek melalui jaringan, percakapan dan membangun komunitas 
(Purnomo,2013). Jika loyalitas merek ini tetap dijaga dan maintance dengan baik maka akan menimbulkan profit jangka panjang bagi perusahaan sesuai penelitian yang dilakukan oleh Talat Mahmood Kiyani (2012).

Berdasarkan latar belakang penelitian yang telah diuraikan, maka dapat dirumuskan masalah penelitian sebagai berikut:

1. Bagaimana gambaran media sosial pada Teh Botol Sosro?

2. Bagaimana gambaran loyalitas merek pada Teh Botol Sosro?

3. Bagaimana pengaruh media sosial terhadap loyalitas merek pada Teh Botol Sosro?

\section{KAJIAN PUSTAKA \\ Bauran Pemasaran (Marketing Mix)}

Pada dasarnya sesuai dengan tujuan pendirian perusahaan, bahwa perusahan harus dapat tumbuh dan berkembang. Hal itu memerlukan strategi pemasaran yang efektif agar mencapai tujuan. Untuk menentukan strategi pemasaran yang efektif diperlukan kombinasi dari elemen-elemen bauran pemasaran. Variabel dalam bauran pemasaran ini akan saling berkaitan satu sama lain.

Menurut MsCharithy yang dikutip oleh Kotler dan Keller (2012:25) "Marketing-mix tools offour broad kinds, which he called the four Ps of marketing: produt, price, palace, and promotion". Bauran pemasaran memiliki empat jenis yang disebut dengan 4P yaitu produk, harga, tempat dan promosi.

\section{MEDIA SOSIAL}

Media sosial menurut Neti (2011) adalah upaya untuk menggunakan media sosial guna membujuk konsumen kepada satu perusahaan, produk atau jasa yang berharga. Pemasaran media sosial adalah pemasaran menggunakan jaringan sosial, blog pemasaran dan banyak lagi.

Kaplan dan Haenlin (2010) mendifinisikan Media Sosial adalah suatu grup aplikasi berbasis internet yang menggunkan ideologi dan teknologi Web 2.0, dimana pengguna dapat membuat atau bertukar informasi pada aplikasi tersebut. Beberapa media sosial yang sangat digemari dan memiliki jutaan pengguna di Indonesia adalah Facebook, Twitter, Instagram, Youtube, Blog, dan lainnya. Sosial media memungkinkan pengguna untuk melakukan komunikasi dengan jutaan pengguna lainnya menurut Williams dkk. (2012).

Menurut Kotler dan Keller (2012:546) media sosial adalah "A means for consumers to share text, images, audio and video information with each other and with companies and vice versa" yang berarti bahwa sosial media adalah sarana bagi konsumen untuk berbagi informasi dalam bentuk teks, gambar, audio dan video dengan konsumen lainnya dan dengan perusahaan atau sebaliknya.

Selain itu, Heuer dalam Brian Solis (2010:262) mengungkapkan bahwa media sosial menggambarkan alat-alat online yang digunakan untuk saling berbagai konten, profil, opini atau pendapat, ilmu atau wawasan, pengalaman, dan perspektif media itu sendiri, sehingga dapat memfasitilasi percakapan dan interaksi online antara kelompok orang.

\section{Dimensi Media Sosial}

Menurut Gurnelius, (2011:16) terdapat empat pilar pemasaran media sosial yaitu:

1. Membaca (read)

Pemasaran melalui media sosial dimulai dengan penelitian, dan pelitian yang harus berkelanjutan. Pemasaran melalui media sosial membutuhkan banyak membaca. Tidak hanya tinggal pada apa yang terjadi dalam industri, tetapi juga perlu disadari dari percakapan online yang sedang berlangsung terjadi hubungan dengan industri, produk, layanan, pelanggan dan pesaing. Membaca dalam berbagai bentuk untuk mencerna informasi sebanyak yang berhubungan dengan bisnis sehingga secara efektif dapat berkomunikasi dengan baik. 


\section{Membuat (creat)}

Buat dan terbitkan konten online yang berguna dan bermakna. Sukses dalam pemasaran media sosial berasal dari mengembangkan percakapan online tentang bisnis, merek, produk, dan promosi dengan menawarkan konten yang menarik minat target audiens.

3. Berbagi (share)

Aspek unik dari media sosial adalah berbagi konten sebagai metode untuk langsung memasarkan bisnis. Pada saat sekarang konsumen telah bergantung pada hubungan, ulasan, rekomendasi dan percakapan sehingga dapat dimanfaatkan untuk berbagi informasi dengan berbagai konten online. Berbagai konten dapat dalam dua bentuk utama. Pertama berbagi konten yang menarik dan berguna ditemukan secara online selama membaca (pilar utama). Dengan menemukan posting blog yang diisi sesuai dengan tips membantu pelanggan. Kedua, berbagai konten yang dibuat (pilar kedua) misalnya, mengupload presentasi melalui slideshare, video di YouTube, dan gambar di Flickr. Berbagai konten sendiri dipublikasikan secara online melalui berbagai alat media sosial. Mempublikasikan sebuah postingan di blog, berbagi melalui twitter, melalui social bookmark, melalui jejaring sosial. Tujuannya adalah berbagi konten ke khalayak yang lebih luas.

\section{Diskusikan (discussion)}

Ketika konsumen berinteraksi dengan pemasar dengan meninggalkan komentar di salah satu posting blog, terhubung dengan pemasar melalui twitter atau jejaring sosial, sangat penting ditanggapi oleh perusahaan. Tidak ada yang suka diabaikan, tapi semua orang suka menjadi pengetahuan positif. dengan kata lain, menunjukan bahwa perusahaan menghargai, menghormati pendapat, dan ingin membangun hubungan dengan konsumen.

\section{LOYALITAS MEREK}

Lau dan Lee

mengemukakan bahwa loyalitas merek telah dikonseptualisasikan sebagai pola aktual perilaku pembelian dari suatu merek atau perilaku niat beli terhadap merek.

Erdogmus dan Cicek (2012) dalam Purnomo (2013) mengungkapkan elemen dari loyalitas merek yaitu niat untuk berinteraksi lebih dengan merek, niat untuk meningkatkan pembelian ulang terhadap merek, niat untuk melakukan interaksi dengan merek melalui media sosial dan niat untuk merekomendasikan merek kepada orang lain.

Menurut Assael (1998) dalam Rajdeep Singh (2016) "as a favorable attitude of the customer towards a brand which is a result of consistent purchase of the brand over time". Artinya sebagai sikap yang menguntungkan dari pelanggan terhadap merek yang merupakan hasil dari pembelian yang konsisten dari merek dari waktu ke waktu".

Menurut Freddy Rangkuti (2009) menjelaskan bahwa loyalitas merek dapat diukur melalui:

1. Pengukuran perilaku (behavior measures)

Cara langsung untuk menentukan loyalitas, khususnya perilaku yang sudah menjadi kebiasaan, adalah dengan mengetahui pola-pola pembelian yang biasa dilakukan oleh konsumen. Pengukuran yang dapat digunakan adalah tingkat pembelian ulang (purchase rate), persentase pembelian dan jumlah merek yang dibeli.

2. Mengukur biaya atau pengorbanan untuk beralih merek ( measuring switching cost)

Analisis terhadap biaya pengorbanan untuk beralih merek dapat memberikan wawasan yang lebih luas karena pengorbanan tersebut merupakan suatu dasar terciptanya loyalitas merek. Apabila konsumen memerlukan pengeluaran yang sangat mahal dan memiliki resiko yang sangat besar hal itu akan mengakibatkan tingkat perpindahannya menjado sangat rendah. 
3. Mengukur kepuasan (measuring satisfaction)

Pengukuran tingkat kepuasan atau mengukur ketidakpuasan merupakan alat yang penting untuk mendeteksi tingkat loyalitas konsumen.

4. Merek kesukaan (Measuring liking brand)

Tahap keempat dari loyalitas melibatkan kesukaan. Kesukaan yang menyeluruh dan umum dapat diukur melalui sebuah brand yang bervariasi, misalnya perhatian, rasa bersahabat, dan kepercayaan. Ukuran lain dari kesukaan tercermin pada kesediaan para pelanggan untuk memperoleh merek kesukaannya, meskipun dengan harga yang lebih tinggi dibandingkan dengan merek lainnya.

5. Komitmen (measuring commitment) Merek-merek yang sangat kuat akan memiliki sejumlah besar pelanggan yang memiliki komitmen. Satu indicator penting adalah jumlah interaksi dan komunikasi yang terlibat dalam suatu produk. Misalnya konsumen suka untuk membicarakan merek tersebut dangan rekannya, bahkan menyarankan dan merekomendasikan untuk membeli merek tersebut.

\section{METODE PENELITIAN}

Berdasarkan tingkat penjelasan dan bidang penelitian, maka jenis penelitian ini adalah deskriptif dan verifikatif. Jenis penelitian yang digunakan adalah metode explanationary survei.

Dalam menentukan jumlah sampel digunakan pengambilan sampel dengan menggunakan simple random sampling dari Al Rasyid (1994:44), yaitu:

$$
n=\frac{\mathrm{n}_{0}}{1+\frac{\mathrm{n}_{0}}{\mathrm{~N}}}
$$

Sedangkan $\mathrm{n}_{0}$ dapat dicari dengan menggunakan rumus sebagai berikut:

$$
\mathrm{n}_{0}=\left[\frac{\mathrm{z}\left(1-\frac{\alpha}{2}\right) \mathrm{s}}{\delta}\right]^{2}
$$

Setelah memperoleh data dari responden yang merupakan populasi penelitian. Penulis mengambil teknik Simple Random Sampling atau pengambilan sampel secara acak, karena populasi dianggap homogeny pada anggota fanpage facebook Teh Botol Sosro.

\section{HASIL DAN PEMBAHASAN}

\section{Tanggapan Responden terhadap Media Sosial Pada Fanpage Facebook Teh Botol Sosro}

Social media sebagai sebuah proses yang memberdayakan individu dan perusahaan untuk mempromosikan website mereka, produk atau layanan online dan melalui saluran sosial untuk berkomunikasi dengan sebuah komunitas yang jauh lebih besar yang tidak mungkin tersedia saluran perikalanan tradisional (Durry, 2008:274). Hasil tanggapan responden bahwa media sosial dengan nilai tertinggi terdapat pada dimensi discussion dengan item pertanyaan promo yang di adakan oleh teh botol sosro sebesar 0,802. Semakin banyak orang berdiskusi dalam sebuah media sosial akan menjadikan kedekatan antara merek dan konsumennya.

\section{Tanggapan Responden terhadap Loyalitas Merek pada Fanpage Facebook Teh Botol Sosro \\ Loyalitas merek dapat didefinisikan} sebagai pelanggan tanpa syarat komitmen dan hubungan yang kuat dengan merek, yang tidak mungkin akan terpengaruh kondisi normal keadaan (Khan dan Mahmood, 2012 p. 33). Sedangkan Freddy Rangkuti (2009) mengemukakan bahwa Brand Loyalty bisa dilihat dari behavior measure, switiching cost, measuring satisfaction, measuring liking brand dan measuring commitment.

Aspek loyalitas merek paling tinggi yaitu terdapat pada dimensi measuring commitment memperoleh skor sebanyak 3723 atau $75,44 \%$, sementara dimensi paling rendah yaitu pada dimensi measuring 
satisfaction yang memperoleh skor 2338 atau $71,06 \%$. Secara keseluruhan variabel loyalitas merek memperoleh skor 14398, apabila di persentasekan kedalam skor ideal maka diperoleh persentase sebesar 72,94\%, dapat dikatakan bahwa sebagian besar responden menyatakan loyalitas merek pada Pada fanpage facebook Teh Botol Sosro dalam kategori cukup puas.

\section{KESIMPULAN DAN SARAN}

Dari hasil analisa dan pengolahan data pada penelitian tentang "Pengaruh Media Sosial terhadap Loyalitas Merek Pada Fanpage Facebook Teh Botol Sosro ”, maka dapat disimpulkan sebagai berikut:

1. Aspek media sosial paling tinggi yaitu terdapat pada dimensi Read memperoleh skor sebanyak 6580 atau $73,94 \%$, sementara dimensi paling rendah yaitu pada Share memperoleh skor 4953 atau 73,13\%. Secara keseluruhan variabel social media memperoleh skor 16913, apabila di persentasekan kedalam skor ideal maka diperoleh persentase sebesar 73,44\%, dapat dikatakan menurut Moch. Ali (1985:184) bahwa hampir seluruh responden menyatakan social media pada fanpage facebook Teh Botol Sosro dalam kategori efektif.

2. Aspek loyalitas merek paling tinggi yaitu terdapat pada dimensi measuring commitment memperoleh skor sebanyak 3723 atau $75,44 \%$, sementara dimensi paling rendah yaitu pada dimensi measuring satisfaction yang memperoleh skor 2338 atau 71,06\%. Secara3. keseluruhan variabel Brand Loyalty memperoleh skor 14398, apabila di persentasekan kedalam skor ideal maka diperoleh persentase sebesar $72,94 \%$, dapat dikatakan menurut Moch. Ali (1985:184) bahwa sebagian besar responden menyatakan Loyalitas Merek pada Pada fanpage facebook Teh Botol Sosro dalam kategori cukup puas. 3. Terdapat pengaruh positif secara signifikan media sosial terhadap loyalitas merek pada Fanpage Facebook Teh BotoIDAFTAR PUSTAKA Sosro.

\section{$5.1 \quad$ Rekomendsasi}

Berdasarkan hasil penelitian, maka penulis merekomendasikan beberapa hal mengenai pelaksanaan media sosial yang dapat meningkatkan loyalitas merek, yaitu:

1. Media sosial yang perlu diperhatikan dalam penggunaannya agar dapat lebih menarik adalah dengan memperbaiki:
a. Konten-konten yang didalam halaman fanpage facebook
b. Tautan yang di bagikan dalam media sosial dibuat lebih menarik dan informatif
c. Dapat menarik perhatian konsumen dalam keanggotaan fanpage facebook agar terlibat dalam diskusi maupun sharing
d. Membuuat lebih banyak promo yang menarik
e. Membuat informasi yang lebih interaktif agar dapat berdialog/diskusi.

2. Didalam loyalitas merek yang perlu diperhatikan agar suatu merek tetap dikonsumsi oleh konsumen adalah dengan cara memperbaiki:

a. Memberikan kenyaman dan keamanan ketika mengkonsumsi produk teh botol sosro agar tidak beralih pada merek lain

b. Tingkat kepuasan yang lebih diperhatikan kepada konsumen

c. Tingkat hubungan atau kedekatan ketika peracaya untuk mengkonsumi merek teh botol sosro.

Menurut penulis PT Sinar Sosro juga harus selalu mengembangkan ide-ide kreatif untuk terus menerus memperbaiki kinerja produk, merek dan mengembangkan media sosial untuk menumbuhkan loyalitas merek dari konsumen teh seiring dengan perkembangan teknologi dan aktif nya konsumen dalam menggunakan internet dimasa yang akan datang. 
Aaker, A David. 2008. Manejemen Ekuitas Merek. Alih Bahasa Oleh Anis Ananada. Jakarta: Mitra Utama.

Ali, Hasan . 2013. Marketing dan KasusKasus Pilihan. Yogyakarta. CAPS (Center For Academic Publishing Service)

Ali Hasan. 2010. Marketing. Yogyakarta : Media Presindo. 2010.

Marketing Dari Mulut ke Mulut Words Of Mouth Marketing.

Al-Rasyid, Harun. 1994. Teknik Penarikan Sampel dan Penyusunan Skala. Bandung:

Universitas Padjadjaran.

Arikunto, Suharsimi. 2009. Prosedur Penelitian Suatu Pendekatan Praktis. Yogyakarta: Bina Aksara

Assael, H. 1998. Consumer Behaviour and Marketing Action $6^{\text {th }}$ edition. New York: International Thomson Publishing.

Buttle, Francis A. 1998. Word of mouth: understanding and managing referral marketing Journal of Strategic MARKETING Vol.6 Hal.241-254. Manchester : Routledge.

Creswell, John W. 2012. Research Design Pendekatan Kualitatif, Kuantitatif dan Mixed. Yogyakarta: Pustaka Pelajar.

Erdogmus, Irem Eren dan Cicek, Mesut. 2012. The Impact of Social Media Marketing on Brand Loyalty. Procedia - Social and Behavioral Sciences 58:1353-1360

Gurnelius, Susan, 2011, 30-minute Sosial Media Marketing, United States: McGraw-Hill Companies

Hasan, A. 2009. Marketing. Yogyakarta: Medpress.
Hermawan, Asep. 2009. Penelitian Bisnis. Jakarta: PT Grasindo

Hurriyati, Ratih. 2010. Bauran Pemasaran dan Loyalitas Konsumen. Bandung: Alfabeta

Kotler, Philip dan Gary Amstrong. 2014. Principle of Marketing $14^{\text {th }}$ edition 14. England: Person Horizon Edition

Kotler, Philip dan Gary Armstrong. 2014. Principle of Marketing $15^{\text {th }}$ edition. New Jersey: Person Pretice Hall.

Kotler, Phipilp. Keller Lane (2012). Marketing Management $14^{\text {th }}$ edition. New Jersey: Pearson Prentice Hall.

Kotler, Philip. Keller Lane (2009). Manajemen Pemasaran jilid 2. Jakarta:Indeks

Lupiyoadi, R. 2013. Manajemen Pemasaran Jasa: Berbasis Kompetensi. Edisi ke tiga. Jakarta: PT Salemba Empat.

Maholtra, Narkesh. 2009. Riset Pemasaran Penerapan Terapan. Jakarta: Gramedia Pustaka Utama.

Maholtra, Narkesh. 2010. Riset Pemasaran Penerapan Terapan. Jakarta: Gramedia Pustaka Utama.

Mayfield, Antony. 2008.(E-book) What is Social Media?. London: iCrossing.

Rangkuti, Freddy. 2009. The Power Of Brand. PT. Gramedia Pustaka Utama: Jakarta.

Riduwan, dan Sunarto. 2009. Cara Muudah Belajar SPSS dan Aplikasi Statistik Penelitian, Bandung: Alfabeta

Sherri, L. Jackson. 2012. Research Method: A Modular Approach $2^{\text {nd }}$ edition Waldsworth /Cengange Learning. 
Siregar, Syofian. 2013 Statistik Parametrik untuk Penelitian Kuantitatif. Jakarta: PT Bumi Aksara

Solis, Brian. (2010). Engage: The Complete Guide for Brands and Business to Build, Cultivate, and Measure Success in the New Web. New Jersey: John Wiley \& Sons Inc.

Sugiyono. 2013. Metode Penelitian Bisnis. Bandung: Alfabeta

Sugiyono. 2014. Metode Penelitian Bisnis. Bandung: Alfabeta.

Tjiptono, Fandy. 2012. Strategi Bisnis Pemasaran. Yogyakarta: Andi

Tjiptono, Fandy dan Gregorius Chandra. 2012. Pemasaran Strategik Yogyakarta: Andi.

Tjiptono, Fandy. (2014). Pemasaran Jasa Prinsip, Penerapan, dan Penelitian Yogyakarta, ANDI OFFSET

Taprial, Varinder \& Priya Kanwar. 2012. Understanding Social Media. London: Ventus Publishing ApS.

\section{Jurnal:}

Amalina, Annisa. 2016. Pengaruh social media terhadap Brand loyalty dengan Brand trust sebagai variabel intervening. Jurnal Ilmu Manajemen. Jurusan Manajemen Fakultas Ekonomi Universitas Negeri Surabaya. Volume 4, No. 3.

Ariadi, Sigit dan Saino. 2014. Pengaruh media sosial twitter terhadap loyalitas merek indosat im3. Jurnal Ilmu Manajemen | Volume 2 Nomor 4 Oktober 2014

As'ad, H. Abu-Rumman. The Impact of Social Media Marketing on Brand Equity: An Empirical Study on Mobile Service Providers in Jordan. Rev. Integr. Bus. Econ.
Res. Vol 3(1) ISSN: 2304-1013

(Online); 2304-1269 (CDROM)

Cakul, Dilek.2015. Fashion Marketing in Social Media: Using Instagram for Fashion Branding.

Buisness\&Management Conference, Vienna, ISBN 978-8087927-13-7,IISES, June 2015.

Chaudhuri, Arjun., Holbrook, M. B. 2001. The Chain of Effect from Brand Trust and Brand Effect to Brand Performance. The Role of Brand Loyalty. Journal of Market Focused Management.

Gecti, Fatih \& Zengin, Hayrettin. 2013. The Relationship Between Brand Trust, Brand Affect, Attitudinal Loyalty and Behavioral Loyalty: A Field Study towards Sports Shoe Consumers in Turkey. No.2. vol 5. Page 111-119.

Jaakonmäki Roope, Oliver Müller dan Jan vom Brocke. The Impact of Content, Context, and Creator on User Engagement in Social Media Marketing.

URI:http://hdl.handle.net/10125/41 289 ISBN: 978-0-9981331-0-2 CCBY-NC-ND

Kaplan A.M \& Haenlein, M. (2010). Users of the world unite! The challenges and opportunities of social media. Business Horisons, 53, 59-68.

Kiyani, Talat Mahmood et al. 2012. The Relationship Between Brand Trust, Customer Satisfaction And Customer Loyalty (Evidence From Automobile Sector of Pakistan. Interdisciplinary Journal of Contemporary Research In Business, Vol. 4, No.1. Komputindo.

Madan, J. and Singh, R., 2010, Formulation and Evaluation of Aloe Vera 
Topical Gels, International Journal of Pharmaceutical Sciences 2(2): 551-555.

Neti, Sisira. 2011. Social Media And Its Role In Marketing. International Journal of Enterprise Computing and Business Systems ISSN. 1:1-15.

Purnomo, Satrio Mulyo. 2013. Pengaruh Twitter Account @Inibaruhidup sebagai Social Media Terhadap Loyalitas Merek Nescafe Indonesia. online, hal.1-9.

Rambe, Patient. 2017. Impact of social media advertising on high energy drink Preferences and consumption. The Journal of Applied Business Research July/August 2017 Volume 33, Number 4

Sheth, Sradha dan Joy Kim. 2017. Social media marketing: the effect of information Sharing, entertainment, emotional connection and Peer pressure on the attitude and purchase intentions. GSTF Journal on Business Review (GBR) Vol.5 No.1, April 2017
Woo Park, Jin. 2013. Investigasting the effect of sales promotion on customer behavioral intentions at duty free shop: an Incheon international airport case study. Journal of airport abd air management. ISSN: 2014-4806

\section{Skripsi:}

Lestari, Isnawati eka. 2016. Pengaruh media sosial terhadap brand equity dan dampaknya pada keputusan pembelian (studi kasus fanspage facebook Hijab elzatta). Program sarjana alih jenis manajemen departemen manajemen fakultas ekonomi dan manajemen. Institut Pertanian Bogor

\section{Website:}

consume! Consumer Buisness Media, diakses 15 Desember 2015

http://www.topbrand-award.com/ pada hari sabtu di akses pukul 12.36 A.M WIB

www.tehbotolsosro.com: Anggota fanpage facebook Teh Botol SosrO 